\title{
Capsule Commentary on Axon et al., Differential Impact of Homelessness on Glycemic Control in Veterans with Type 2 Diabetes Mellitus
}

\author{
Matthew J. Crowley, MD, MHS \\ Center for Health Services Research in Primary Care, Durham Veterans Affairs Medical Center, Durham, NC, USA.
}

$\mathrm{J}$ Gen Intern Med 31(11):1357

DOI: $10.1007 / \mathrm{s} 11606-016-3819-7$

() Society of General Internal Medicine 2016

\begin{abstract}
A xon et. al used a large longitudinal database to characterize the relationship between homelessness and glycemic control among veterans with type 2 diabetes. ${ }^{1}$ The authors found that homelessness was associated with poor glycemic control across racial/ethnic groups during the observation period. The magnitude of this association was greatest in Hispanic patients and lowest in non-Hispanic blacks. The authors conclude that homelessness is a significant risk factor for uncontrolled diabetes in veterans, and suggest the need for broader efforts targeting diabetes management in homeless populations.
\end{abstract}

As a result of this analysis, we can add homelessness to the long list of factors known to be associated with poor diabetes control. These include factors highlighted by the authors (material need insecurity, food insecurity) and many others, including race, lack of health insurance, medication non-adherence, and depression. ${ }^{2-4}$ All of these factors are highly germane to homeless populations, and may even mediate the observed relationship between homelessness and uncontrolled diabetes. Given the many urgent challenges homeless persons face, it is easy to see how diabetes control may be a low priority. The short-term sequelae of uncontrolled type 2 diabetes pale beside competing needs that are fundamental to survival, like finding food and safe shelter.

Unfortunately, another issue compounds the challenge of diabetes management for homeless individuals; while available approaches to improving diabetes control are demanding even for highly resourced patients, they are often unrealistic for the homeless. For example, guidelines recommend insulin initiation when simpler measures do not adequately lower HbA1c. ${ }^{5}$ However, for patients who lack access to refrigeration and cannot afford insulin pens or testing supplies, insulin may be a poor option. Other approaches to improved diabetes control often utilize frequent clinic visits, telephone- or web-based contact, or use of advanced monitoring technologies, all of which may be unattainable for homeless persons.

While it is important to recognize that homeless persons have high rates of uncontrolled diabetes, there is likely no purely medical solution to this problem. This paper adds to the chorus of compelling arguments for committing as a society to the elimination of homelessness.

Corresponding Author: Matthew J. Crowley, MD, MHS; Center for Health Services Research in Primary CareDurham Veterans Affairs Medical Center, Durham, NC, USA (e-mail: matthew.crowley@dm.duke.edu).

\section{Compliance with Ethical Standards:}

Conflict of interest: The author has no conflicts of interest with this article, and is supported by a Career Development Award from VA Health Services Research and Development (CDA 13-261).

\section{REFERENCES}

1. Axon RN, Gebregziabher M, Dismuke CE, Hunt KJ, Yeager D, Santa Ana EJ, Egede LE. Differential Impact of Homelessness on Glycemic Control in Veterans with Type 2 Diabetes Mellitus. J Gen Intern. doi:10.1007/s11606016-3786-Z

2. Ali MK, Bullard KM, Imperatore G, et al. Division of Diabetes Translation, National Center for Chronic Disease Prevention and Health Promotion. Characteristics associated with poor glycemic control among adults with self-reported diagnosed diabetes - national health and nutrition examination survey, United States, 2007-2010. MMWR Surveill Summ. 2012;61:32-37.

3. Crowley MJ, Holleman R, Klamerus ML, Bosworth HB, Edelman D, Heisler M. Factors associated with persistent poorly-controlled diabetes mellitus (PPDM): clues to improving management in patients with resistant poor control. Chronic Illn. 2014;10:291.

4. Richardson LK, Egede LE, Mueller M, Echols CL, Gebregziabher M. Longitudinal effects of depression on glycemic control in veterans with type 2 diabetes. Gen Hosp Psychiatry. 2008;30:509-514.

5. American Diabetes Association. Standards of medical care in diabetes-2016. Diabetes Care. 2016;39:S1-S112.

Published online August 8, 2016 